\title{
Comparison of Klinkenberg-Corrected Gas and Liquid Permeability in Kirthar Fold Belt Tight Gas Sands
}

\author{
AFTAB AHMED MAHESAR*, KHALIL REHMAN MEMON*, AND HAFEEZ-UR-RAHMAN MEMON*, \\ AND ABDUL HAQ TUNIO*
}

RECEIVED ON 17.11.2016 ACCEPTED ON 21.02.2017

\begin{abstract}
A detailed laboratory study was carried out to investigate the controls and differences between Klinkenbergcorrected gas and liquid permeability. For this reason outcrop core samples were collected from Kirthar fold belt of lower Indus basin, the plugs were horizontally taken, in cylindrical shape having dimension of 3.5-5.32 cm length and with maximum of $3.2 \mathrm{~cm}$ diameter. The sample porosity measurements were performed using calculations from grain volume and bulk volume method. For the purpose of comparison, slippage free gas permeability tests using nitrogen gas was measured and liquid permeability of samples was measured using brine $(\mathrm{NaCl})$ of different compositions. The data obtained showed that liquid permeability was lower by an order of magnitude than the permeability of samples measured with gas. However, the gas permeability corrected for Klinkenberg effects showed difference of half an order of magnitude when compared with liquid permeability. Hence the differences in liquid permeability and gas permeability could be described by other mechanism of particles mobilization and dissolution and pore blocking phenomena. Moreover, the obtained data of gas and liquid permeability was then used to develop permeability estimation correlations. The results suggests that there is scatter in the measured values and predicted values of gas and liquid permeability data, which means that such correlations should not be used where accurate liquid permeability values of tight sandstones are needed. Permeability predicted using the existing correlations developed based on gas permeability data lead to an overestimation of permeability also the flow rates might be over predicted within such low permeability reservoirs.
\end{abstract}

Key Words: Tight Gas Sands, Brine, Permeability, Stress Sensitivity

\section{INTRODUCTION}

7 he permeability is the main property of any reservoir rock, which controls the fluid flow and is an essential parameter for modeling reservoir production behavior. Permeability to liquid either brine or distilled water are generally not present for most of the reservoirs; as it is difficult to obtain because it takes a lot of time to reach stabilized flow rates and pressure differentials [1-2]. Hence; if liquid permeability is needed for input into reservoir modeling, the reservoir engineers generally obtain this by making equivalent to slippage 
corrected gas permeability values of routine core analysis [3-4]. However, gas permeability measured in laboratory always show higher value than absolute liquid permeability for the same sample [3-5]. Many of the previous studies have reported correlations between gas permeability and liquid permeability which were performed on sandstones samples [5-6]. The main difference in the pore system of samples between sandstones and other reservoirs could be the pores itself and pore; throat internal structure [2-5,7-8]. For sandstone, high to medium porosity has spherical internal pore structure with high to medium aspect ratio (pore body to throat size ratio). It is also reported that the samples with less clay minerals, clay contents have higher permeability, in which pores with low aspect ratio if filled with sand grains, and are not completely spherical, also lead to low permeability [7-9].

The objective of this study was to develop correlation in between gas and liquid permeability values based on the data obtained in laboratory for the tight rocks of Kirthar fold belt area Sindh Pakistan. The core samples in fact are the ground reality in understanding and exploitation of hydrocarbon resources [9-11]. The petro physical properties and geological attributes of rocks encompass the operator to realize the production potential of a reservoir and map out the best scenarios for optimal field development. Moreover; the authors [11-12] reported that the influence of confining stress related to permeability of few tight sand samples was also studied.The permeability stress sensitivity results for these samples will be useful for providing a sound basis of the Kirthar fold tight gas potential development [13-14].

The tight gas potential of Pakistan tight gas reservoirs is very challenging technically and commercially [10]. Hence, for this reason it is essential to perform detailed petro physical analysis and to produce gas from such low permeability reservoirs at commercial rates. Gas production from tight gas reservoirs ranges from 2 MMscfd to few thousand cubic feet $[10,13]$. Hence it is essential to hydraulically fracture these reservoirs and it is the most critical technique in tight-reservoirs development [14-15]. The many of the low permeability reservoirs productivity is being raised to the level of their commercial production rate by hydraulic fracturing. "A gas reservoir estimated value of average permeability if it is less than 0.1md [16-17] with initial wellhead absolute flow potential (flow at atmospheric pressure at the well head) of less than or equal to 5 MMscfd" [15-18].

Due to sufficient availability of unconventional gas resources, no resource assessment for tight gas and other non-conventional resource has been carried out in Pakistan. However, the situation is changing due to growing energy deficit [9-10,16-19]. Gas is the dominant component of conventional energy supply of the country, which is projected to decline from 4 BCFD in 2008 to 1.6 BCFD in 2022 giving rise to deficit of 7.2 BCFD, which is almost twice the current production level. This demand is not expected to be met by the conventional gas plays, and has necessitated the need to look for nonconventional indigenous gas resources such as tight gas. This study aims to investigate permeability of tight gas sands so that the marginally profitable reservoirs productivity can accurately be assessed, so that the uncertainties can be decreased in commercial extraction of these readily available gas resources [15,19-20].

Gas in excess of 40TCF (Trillion Cubic Feet) might be lying un-tapped in the TGR (Tight Gas Reservoirs) of Pakistan based on exploration activities carried out in the mature basins of Pakistan and is expected that there might be substantial rise in gas resources . Based on the drilling and preliminary assessment of the industry, there are substantial tight gas reservoirs in the existing plays of Pakistan, summarized in Table 1 [16,20-21]. 
The purpose of this study was to assess the extent of variations in between gas and liquid permeability, that might exists either due to the gas slippage effects or could be due to other reason such as physiochemical reactions with water as a pore fluid. Moreover, the other aim was to develop a correlation by which a liquid permeability could be estimated from gas permeability values. To attain these objectives the permeability of samples collected from Kirthar fold belt outcrop were obtained, initially the permeability was measured using dry gas (nitrogen gas) and then the samples were flooded with brines of different concentrations, finally the permeability measured using demineralized water. As the nitrogen gas is non-reactive does not reacts with the samples grain surfaces and is chemically non-reactive compared with demineralized water (distilled water). The measured liquid and gas permeability corrected for slippage effects was then compared each other [10-21].

\section{GEOLOGICAL SETTINGS}

The samples collection location is specified with Fig. 1 of Kirthar Fold Belt and is located in (West Pakistan Fold Belt) [10]. This imparts a good formation (outcrop) and is realized to have good potential of hydrocarbon reserves as well as having good trapping mechanism [10,21-22]. Kirthar Fold Belt, the Pab Formation is part of sedimentary succession. The thick marine siliciclastic pab formations of Kirthar fold ranges from 50-450m. These mostly consist of sandstone of inter bedded with marl and mudstones. The sandstone is yellow, grey light brown and greenish, which is medium to coarse gained moderate well sorted,

TABLE 1. EXISTING TIGHT GAS POTENTIAL WITHIN THE PAKISTAN [19]

\begin{tabular}{|c|c|c|c|c|}
\hline Basin & Block & Prospects & Reservoir & GIIP (bcf) \\
\hline Middle Indus & 8 & 11 & 7 & 15000 \\
\hline Sulaiman Foldbelt & 4 & 7 & - & 19000 \\
\hline Kirthar Foldbelt & 7 & 8 & 2 & 7300 \\
\hline Total & 19 & 26 & 9 & 41300 \\
\hline
\end{tabular}

well rounded to sub rounded. Marl is very thin-bedded light grey and is laminated finely. Mudstone is bio-turbated and is brownish reported two depositional systems. One is shallow marine and other one is fluviodeltaic to deep marine turbidites. There were three facies were recognized as transitional proximal to distal settings, as the deep shelf facies and shore face associations in the North depositional system [20,23-24].

\section{EXPERIMENTAL PROCEDURE}

(1) The plugs were taken horizontally to the bedding section of samples obtained, near Kirthar fold belt outcrop in district Dadu Sindh, Pakistan. About 3.5-5.90 cm length and with maximum diameter of $2.8 \mathrm{~cm}$ cylindrical shape plug samples were taken.

(2) After plugging the samples were cleaned in a Soxhlet extractor for removal of any of the contaminated fluids and residues. The samples were then placed into oven for about 48 hours for drying purposes.

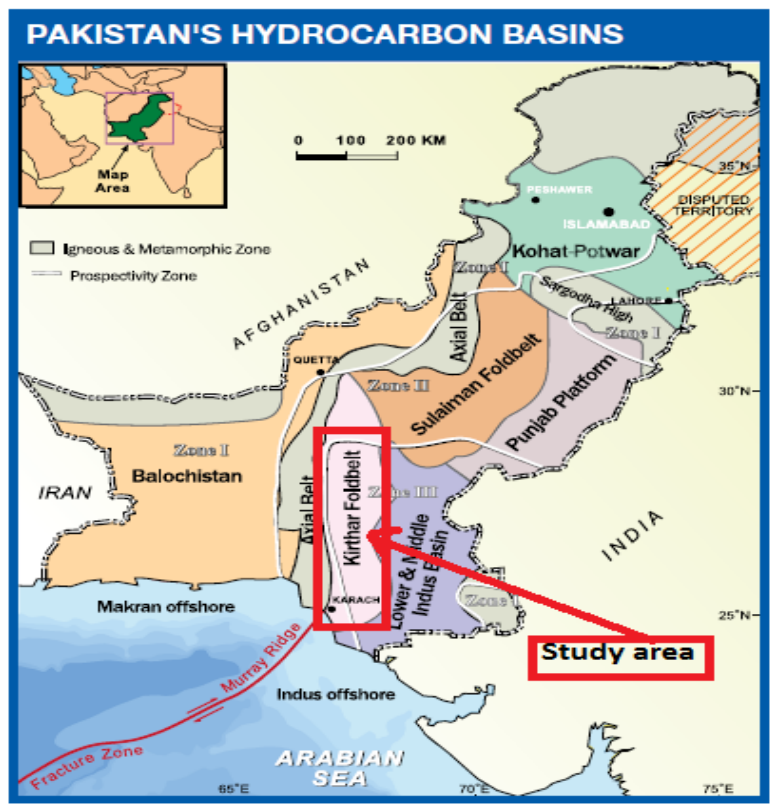

FIG. 1. THE STUDY AREA REPRESENTED IN THIS MAP [19]

Mehran University Research Journal of Engineering \& Technology, Volume 36, No. 4, October, 2017 [p-ISSN: 0254-7821, e-ISSN: 2413-7219] 
(3) The measurements were performed using helium gas as a pore fluid for gas permeability measurement and ( $\mathrm{NaCl})$ brine of $5 \%$.

(4)

The porosity measurements were performed by calculations, from GV (Grain Volume) and BV (Bulk Volume). The BV, was determined by measuring the sample diameter and length with caliper as well as weighing the water saturated sample while immersing into water using Archimedes principle. GVs of sample plugs were obtained using a helium porosimeter. However; the BV calculations were performed using the digital Vernier caliper by determining the dimensions of the samples. Around the three measurements of lengths and diameters were taken for accuracy and minimization of error in calculated values.

The porosity was determined using following Equation (1):

$\phi=\frac{B V-G V}{B V}$

Where $\phi$ is porosity in percentage or in fractions, BVand GV.

For brine permeability measurements $(\mathrm{NaCl})$ brine solutions of 5\%was prepared in the laboratory. These brines were prepared based on reported formation waters. The brine solutions were filtered by using $0.40 \mathrm{~mm}$ filter paper and the brine were degassed in a vacuum apparatus for removing the air prior to use for permeability measurement. Viscosity of the brine samples was measured separately using the Rolling ball viscometer. For each core samples the steady state permeability was obtained using four flow rates, calculations were followed by the application of Darcy's equation. The steady state gas permeability experimental setup is shown in Fig. 2; few samples of very low permeability were measured with pulse decay experimental setup of Core lab. The pulse decay experimental set-up outline is also presented in Fig. 3. The permeability was calculated using following Equation (1):

$k_{a}=\frac{2 \mu L_{s} Q_{a} P_{a}}{A_{s}\left(P_{1}^{2}-P_{2}^{2}\right)}$

Where $\mu$ is the viscosity of the fluid flows across sample; $\mathrm{L}$ is the length of the samples in centimeters, $\mathrm{Q}$ is the flow rate in cc/sec, $\mathrm{P}$ is the pressure in atm and $\mathrm{A}$ is the crosssectional area of sample in $\mathrm{cm}^{2}$.

The liquid permeability was measured using brine of $\mathrm{NaCl}$, experiments were performed by flowing brine of $5 \% \mathrm{NaCl}$

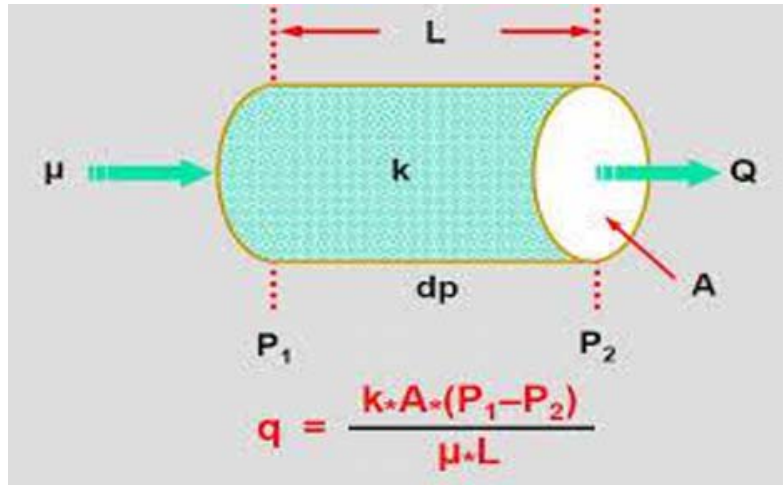

FIG. 2. DIAGRAM SHOWS THE STEADY STATE GAS PERMEABILITY SETUP

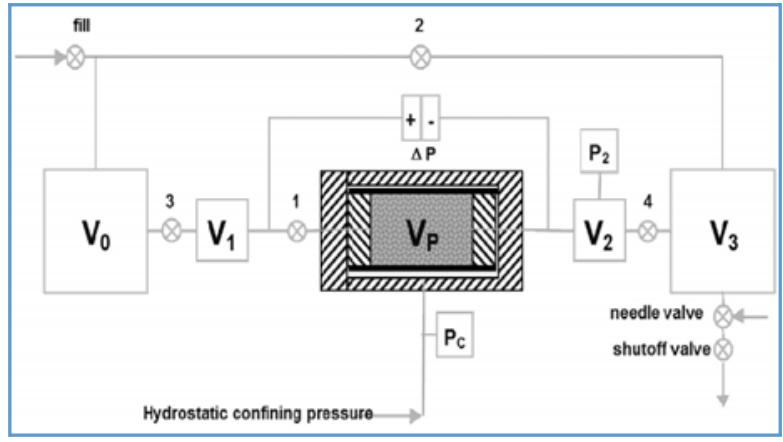

FIG. 3. PULSE-DECAY APPARATUS FOR UNSTEADY-STATE PERMEABILITY MEASUREMENT TO GAS [31]

Mehran University Research Journal of Engineering \& Technology, Volume 36, No. 4, October, 2017 [p-ISSN: 0254-7821, e-ISSN: 2413-7219] 
across the samples. The pressure drop at each flow rate was recorded. A graph between pressure drop across samples versus flow rate was developed for each core plug to make sure that intersect at zero (Fig. 4).The permeability measurements were performed at ambient temperature, and viscosity was calculated at the measured temperature. Following Equation (3) was used for liquid permeability calculations:

$K=\frac{Q \mu L}{A(P 1-P 2)}$

Where $\mathrm{Q}$ is the flow in cc/sec, $\mathrm{A}$ is the cross-sectional area of the sample in $\mathrm{cm}^{2}, \mu$ is the viscosity of sample and $\mathrm{P} 1$ and $\mathrm{P} 2$ are the upstream and downstream pressure in $\mathrm{atm}$.

\section{RESULTS AND DISCUSSION}

In this study permeability measurements were made on samples supplied from Kirthar fold belt tight gas sands, with results presented in Table 2. Porosity-permeability results as a cross-plot are shown in Fig. 5. Presenting a type I and II rock facies. In addition to one of the sample permeability was circled as outlier. This sample could be fractured however, it is recommended to perform micro scanning using electronic microscope by preparing thin sections.

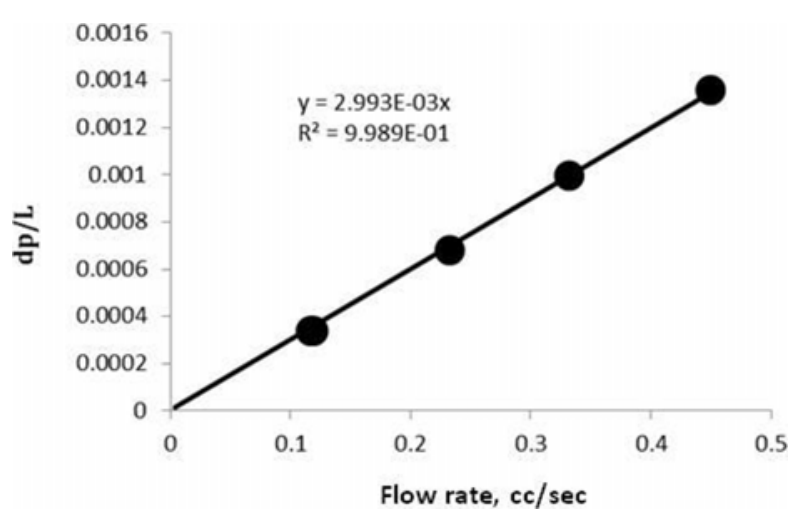

FIG.. 4. A TYPICAL PRESSURE DROP VERSUS FLOW RATE FOR ONE OF THE SAMPLE
Fig. 6 provides the results from permeability measured at different net confining stresses. The experiments initially performed at lower confining stress of 500 psi and gradually increased to high confining stress upto 2500 psi. The geometric mean of the permeability to gas is $0.209 \mathrm{mDarcy}$ and for brine permeability is $0.080 \mathrm{mDarcy}$ (Table 2).

TABLE 2. BASIC PETROPHYSICAL PROPERTIES OF KIRTHAR FOLD BELT SAMPLES

\begin{tabular}{|c|c|c|c|}
\hline Sample & $\mathrm{Kg}(\mathrm{mD})$ & $\mathrm{Kb}$ & $\mathrm{Kg} / \mathrm{Kb}$ \\
\hline $\mathrm{KT} 1$ & 1.02 & 0.89 & 0.36 \\
\hline $\mathrm{KT} 2$ & 5.43 & 2.56 & 2.27 \\
\hline KT3 & 3.66 & 1.60 & 2.29 \\
\hline KT4 & 6.89 & 5.04 & 1.37 \\
\hline
\end{tabular}

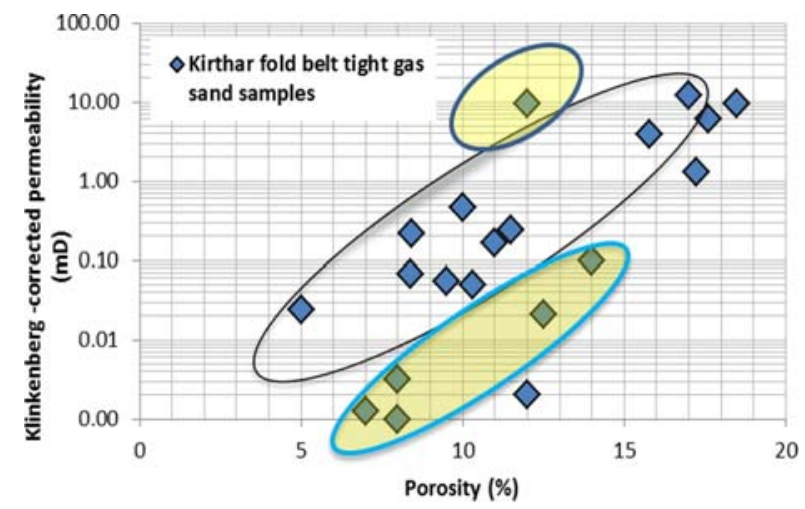

FIG. 5. PERMEABILITY VERSUS POROSITY RELATION FOR ALL SAMPLES STUDIED

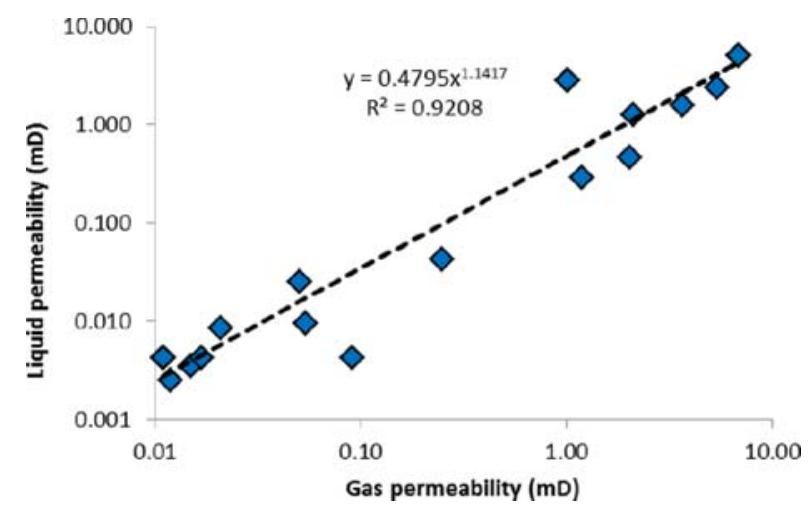

FIG. 6. GAS AND LIQUID PERMEABILITY DATA OF KIRTHAR FOLD BELT SINDH PAKISTAN

Mehran University Research Journal of Engineering \& Technology, Volume 36, No. 4, October, 2017 [p-ISSN: 0254-7821, e-ISSN: 2413-7219] 
Moreover; slippage-corrected gas permeability and liquid permeability data were plotted on a log-log plot and a power regression was employed to establish a correlation (Fig. 6).The results showed a difference of half an order magnitude and the brine permeability was 5-10 times less than gas when measured on the same core plug. The plotted data revealed a direct proportionality relationship (Fig. 6). Slippage corrected gas permeability plotted against liquid had shown that the gas permeability is high compared to liquid permeability. The samples with lower permeability values have shown more reduction when measured with liquid permeability compared to gas permeability. The other possible reason could be the sample dimensions. If length of the core sample is less than the diameter of samples then it will disobey Darcy's assumption [23-26]. Such differences in permeability values provide the relative control of fluid flow within tight sand reservoirs. The dissimilarity observed in permeability of sandstones using different pore fluids could be the physiochemical reactions between water and clay mineralogy .It was assumed that the presence of clay mineralogy could be the reason of reduced liquid permeability, as it can result in formation of layer of clay bound water on the grain surfaces of samples. The low permeability samples would be more affected by layer of clay bound water, as clay swelling occur, which results in lessening of size of the pore throat resulting in reduced area for flow of fluid, consequently reduction in permeability [25,27-30].

Based on the gas and permeability data a correlation was established Equation (4) to predict liquid permeability. The fitted results are also shown in Fig. 6.

$\mathrm{K}_{\text {liquid }}=0.479 \mathrm{~K}^{1.14}\left(\mathrm{R}^{2}=0.92\right)$

\subsection{Validation of the Derived Correlation}

The correlations were validated based on the data of core samples measured in the laboratory. Various samples from the Lower Indus basin of Kirthar fold belt formation were used for the development of the correlation.
The relation of brine and gas permeability of tight gas sands developed is shown in Fig. 4. Utilizing the permeability data from both gas and liquid a general equation was derived (Equation (4)), which shows the relation between two measurements i.e. the gas permeability and brine permeability (Fig. 6).

\subsection{Overburden Stress Influence on Permeability}

The measured permeability of tight gas samples from all plugs was plotted against net confining stress and is shown in Fig. 7. In this plot, 'y' axes correspond to the permeability measured at 2500 psi confining pressure and the ' $x$ ' axes is permeability which is measured at net confining pressure of 500psi. It can be seen from the data plotted in Fig. 7 that there is a greater degree of permeability reduction with low permeability cores than samples having high permeability. In core samples with initial absolute gas permeability less than $<0.1 \mathrm{mDarcy}$, the permeability in those samples significantly decreased at high net confining pressure of 2500psi. This behavior could be compared with other tight gas formations, which exhibit permeability, lower than $0.1 \mathrm{mDarcy}$. The reduction in permeability observed in present study is also similar to that of the [26-30]. The trend line black colored on Fig. 8 is the power law fit of the data points on the log-log plot, which also shows that the permeability with less than $1 \mathrm{mD}$ is more sensitive to confining stress. However; there is a moderate impact on brine permeability reduction was observed compared to the gas permeability of the samples studied. Reduction in permeability due to stress increase is reported in Fig. 7. The reduction in permeability in tight gas samples from Kirthar fold belt cannot be generalized for all types of low permeability reservoirs, as every reservoir will let fluid flow differently based on their composition and mineral contents as well depositional environment. By increased confining stress, the permeability of these samples showed reduction particularly for samples having very low absolute initially permeability. More work is required to provide reasons for reduction in permeability due to stress increase.

Mehran University Research Journal of Engineering \& Technology, Volume 36, No. 4, October, 2017 [p-ISSN: 0254-7821, e-ISSN: 2413-7219] 


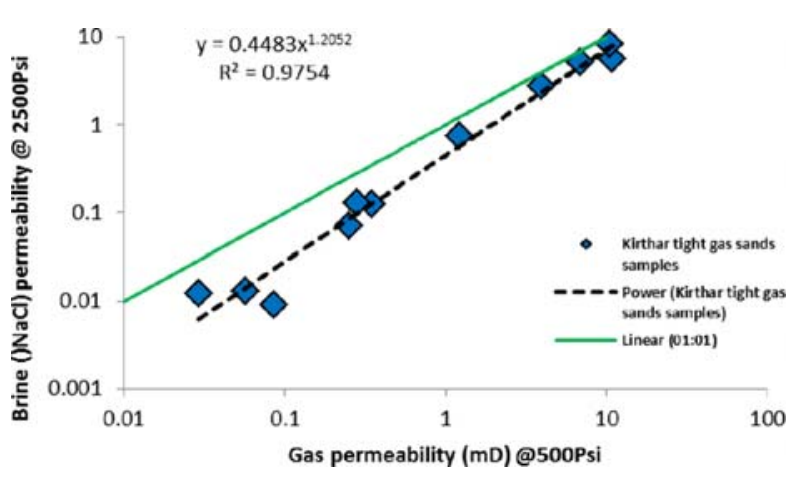

FIG. 7. PLOT IS THE GASPERMEABILITY OFFIVE SAMPLES MEASURED UNDER STRESS CONDITIONS

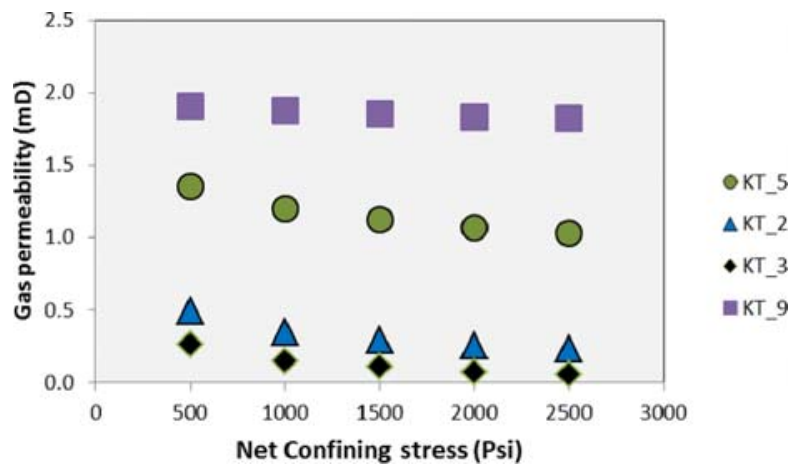

FIG. 8. PERMEABILITY RESULTS PLOTTED AT AMBIENT STRESS OF 500 VERSUS IN-SITU STRESS OF 2500PSI OVERBURDEN STRESS

\section{CONCLUSION}

The gas and liquid permeability of samples collected from Kirthar fold belt conducted using different pore fluids (e.g. $\mathrm{NaCl}$ brines of different composition and distilled water). The results were compared and the following conclusions were drawn:

(i) Gas permeability is higher than brine permeability's gas permeability values are around 5-10 times those values measured by distilled water.

(ii) There was around half an order of magnitude difference in gas and brine permeability of the samples studied from Kirthar fold belt sands. The permeability measured with brine was lower, particularly for those samples, which have less than $0.1 \mathrm{mDarcy}$ permeability.

(iii) The equation derived for liquid permeability estimation, and the validity was tested utilizing the existing data sets of the measured permeability that were available in our database, it was found that there was $0.50 \%$ error which seems to be negligible.

(iv) Permeability of samples measured showed sensitivity to stress; the less permeable samples were more sensitive to stress particularly those samples which were having less than $0.1 \mathrm{mDarcy}$ absolute permeability. For further stress sensitivity analysis it is recommended to run more permeability experiments on several different samples at different stress conditions.

\section{ACKNOWLEDGEMENT}

The authors acknowledge support from number of people who made this manuscript possible including: parents, teachers, and friends. Authors are also indebted to their parental institutes, Mehran University of Engineering \& Technology, Jamshoro, Pakistan, who provided the opportunity to produce this paper.

\section{REFERENCES}

[1] Al-Muthane, A.S., "Best Practices in Conventional Core Analysis a Laboratory Investigation”, Society of Petroleum Engineers, Section Technical Symposium, Alkhobar, Saudi Arabia, 10-12 May, 2008.

[2] Al-Jabri, R.A., Al-Maamari, R.S., and Wilson, O.B., "Klinkenberg-Corrected Gas Permeability Correlation for Shuaiba Carbonate Formation”, Journal of Petroleum Science \& Engineering, Volume 131, pp. 172-176, 2015.

[3] Amthor, J., Kerans, C., and Gautheir, P., "Reservoir Characterization of a Shu'aiba Carbonate Ramp-Margin Field, Northern Oman”, Barremian-Aptian Stratigraphy and Hydrocarbon Habitat of the Eastern Arabian Plate, 2010.

[4] Bloomfield, J., and Williams, A., “An Empirical Liquid Permeability-Gas Permeability Correlation for Use in Aquifer Properties Studies”, Quarterly Journal of Engineering Geology and Hydrogeology, Volume 28 (Supplement-2), pp. S143-S150, 1995.

[5] Macary, S.M., "Conversion of Air Permeability to Liquid Permeabilities Extracts Huge Source of Information for Reservoir Studies", Proceedings of Conference on Petroleum Science and Engineering, Middle East Oil Show, pp. 65-71, 1999.

[6] Ambrose, R.J., Hartman, R.C., Diaz Campos, M., Akkutlu, I.Y., and Sondergeld, C., "New Pore-Scale Considerations for Shale Gas in Place Calculations", Proceedings of Conference on Society of Petroleum Engineers Unconventional Gas, 2012. 
Pugh, V.J., "Correlations of Liquid anc Air Permeabilities for Use in Reservoir Engineering Studies”, Log Analyst, 1991.

Tanikawa, W., and Shimamoto, T., "Klinkenberg Effect for Gas Permeability and its Comparison to Water Permeability for Porous Sedimentary Rocks”, Hydro Earth System, Science, pp. 1315-1338, 2006.

Raza, H.A., Ahmed, R., Ali, S., Sheikh, A., and Shafique, N., "Exploration Performance in Sedimentary Zones of Pakistan”, Pakistan Journal Hydrocarbon Research, Volume 1, pp. 1-7, 1989.

Kadri, I., "Petroleum Geology of Pakistan: Pakistan Petroleum Limited”, Karachi, Pakistan, 1995.

Brace, W.F., Walsh, J., and Frangos, W., "Permeability of Granite Under High Pressure”, Journal of Geophysical Research, Volume 73, No. 6, pp. 2225-2236, 1968

Coward, M.P., and Johnson, H., "Structural Geology in Reservoir Characterization”, 1998

Zhang, M., Takeda, M., Esaki, T., Takahashi, M., and Endo, H., "Effects of Confining Pressure on Gas and Water Permeabilities of Rocks”, Proceedings Materials Research Society Symposium, Cambridge University Press, pp. 851-860, 2002

Shar, A.M., and Mahesar, A.A., "Pakistan’s Kirthar Fold Belt Show Development Potential”, Oil and Gas Journal, Volume 114, No. 12, 2016.

Unconventional Resources in Pakistan, Internal Documents of Ministry of Petroleum and Natural Resources, 2012.

Jones, F.O., and Owens, W., “A Laboratory Study of Low-Permeability Gas Sands”, Journal of Petroleum Technology, Volume 32, No. 9, pp. 1,631-631, 980.

McDougall, J.W., and Hussain, A., "Fold and Thrust Propagation in the Western Himalaya Based on a Balanced Cross Section of the Surghar Range and Kohat Plateau, Pakistan (1)”, AAPG Bulletin, Volume 75, No. 3, pp. 463-478, 1991.

[18] Heid, J., McMahon, J., Nielsen, R., and Yuster, S., "Study of the Permeability of Rocks to Homogeneous Fluids", Proceedings of Drilling and Production Practice, American Petroleum Institute,1950.

[19] DGPC (Directorate General of Petroleum Concessions) Pakistan, Petroleum, Exploration and Production Policy, Ministry of Petroleum and Natural Resources, Islamabad, Pakistan, (Accessed, 27 April, 2011).

[20] Khan, A., Kelling, G., Umar, M., and Kassi, A., "Depositional Environments and Reservoir Assessment of Late Cretaceous Sandstones in the South Central Kirthar Foldbelt, Pakistan”, Journal of Petroleum Geology, Volume 25, No. 4, pp. 373-406, 2002.
Viqar-un-nisa, Q.S., "Hydrocarbon Prospects of Southern Indus Basin, Pakistan”, AAPG Bulletin, Volume 70, No 6, pp. 730-747, 1986.

[22] Kawata, Y., and Fujita, K., "Some Predictions of Possible Unconventional Hydrocarbons Availability Until 2100”, Proceedings of Society of Petroleum Engineers Asia Pacific Oil and Gas Conference and Exhibition, 2003

[23] Loznyuk, O., Surtaev, V., Sakhan, A., Murtazin, R., Latkin, K., Sitdikov, S., Pestrikov, A., Gusakov, V., Politov, M., and Yudin, A., "A Multistage Stimulation Operation to Unlock the Gas Potential of the Turonian Siltstone Formation in Western Siberia”, Proceedings Conference on Society of Petroleum Engineers Russian Petroleum Technology.

[24] Civan, F., Rai, C.S., and Sondergeld, C.H., "Shale-Gas Permeability and Diffusivity Inferred by Improved Formulation of Relevant Retention and Transport Mechanisms”, Transport in Porous Media, Volume 86, No. 3, pp. 925-944, 2011.

[25] Lushev, M., Markin, M., Dubnitskiy, I., and Vorobyev, V., "Determining Methods of Static Mechanical Properties of Poorly Consolidated Sand-Rocks (by the Example of the Yuzhno-Russkoye Field)", Proceedings of Confreence on Society of Petroleum Engineers Russian Petroleum Technology, Society of Petroleum Journal, 2015.

[26] Mulkamanov, A., Dorofeev, A., Vorobyev, V., Bolshakova, A., Chupeev, A., Sauve, R., Tonkin, T., and Vernus, J., “Integrating Asset Modelling for Strategic Gas Field Development Planning and Short-Term Optimization”, Proceedings of Conference on Society of Petroleum EngineersRussian Petroleum Technology, Society of Petroleum Journal, 2015.

[27] Sampath, K., and Keighin, C.W., "Factors Affecting Gas Slippage in Tight Sandstones of Cretaceous Age in the Uinta Basin”, Journal of Petroleum Technology, Volume 34, No. 11, pp. 2,715-712,720,1982.

[28] Faulkner, D.R., and Rutter, E.H., "Comparisons of Water and Argon Permeability in Natural Clay-Bearing Fault Gouge under High Pressure at 20 Degrees C”, Journal of Geophysical. Research, Volume 105, No. 16, pp. 415-16 426, 2000.

[29] Jones, S.C., “A Rapid Accurate Unsteady - State Klinkenberg Parameter”, Society of Petroleum Engineers Journal, pp. 383-397, 1972.

[30] Klinkenberg, L.J., "The Permeability of Porous Media to Liquids and Gases”, American Petroleum Institute, Drilling and Productions Practices, pp. 200-213, 1941.

[31] James, S.C., “A Technique for Faster Pulse-Dacay Permeability Measurements in Tight Rocks”, Society of Petroleum Journal, pp. 19-26, 1997. 